\title{
Inter-relationship between footprints and photogrammetry
}

\author{
Francisco Valmor Macedo Cunha', Tárik Augusto Amorim Rodrigues², Jonas Almeida Alves ${ }^{3}$, Jean Douglas Moura Santos ${ }^{4}$,
} Maria do Carmo Carvalho Martins ${ }^{5}$

\begin{abstract}
Introduction: Alterations in foot landing position have often been associated with the appearance of deformities in lower limbs. However, there are no studies that prove the relationship between these two variables in healthy individuals. Objective: To investigate the relation between changes in feet and lower limbs by plantigraphy and computerized photogrammetry. Methods: The study included 70 young adults, 42 women (height: $1.60 \pm 0.01 \mathrm{~m}$; body weight: $58.0 \pm 0.92 \mathrm{~kg}$; body mass index: $22.0 \pm 0.31 \mathrm{~kg} / \mathrm{m}^{2}$ ) and 28 men (height: $1.70 \pm 0.01$ m; body weight: $70.0 \pm 1.4 \mathrm{~kg}$; body mass index: $23.0 \pm 0.42 \mathrm{~kg} / \mathrm{m}^{2}$ ) with mean age of $21.62 \pm 2.0$ and $22.18 \pm 2.09$ years, respectively. Plantigraphy of both feet and photographic capture in the anterior frontal plane of lower limbs and foot, posterior frontal of the tendon of the calcaneus and in the sagittal plane of lower limbs were performed. Results: A strong positive correlation was observed between the Chippaux-Smirak and the Staheli indexes (Men- $r: 0.863$ and $p<0.001$; Women- $r: 0.973$ and $p<0.001$ ) and a weak positive correlation between the malleolar angle and the Cavanagh-Rodgers index (Men- r: 0.386 and p 0.003; Women-r: 0.280 and p 0.010). Conclusion: There was no correlation between footprint indexes and lower limb angles measured by computerized photogrammetry. Keywords: photogrammetry; lower limb; foot; posture; medial longitudinal arch.
\end{abstract}

\section{INTRODUCTION}

The foot typology suffers multiple interferences of intrinsic and extrinsic factors, among the intrinsic factors are age, gender, stature, body weight, pregnancy and diabetes, and among the extrinsic are the type of footwear and the surface. However, what stands out are the angular and rotational alterations in the lower limbs triggered by changes in the foot typology. . $^{(1,2,3)}$

Among the triggering factors for such alterations, are highlighted those related to the medial longitudinal arch, which can trigger a "pathophysiological cascade" that may result in changes in alignment and angulation of the joints and supra-located structures. ${ }^{(4)}$ Carvalho ${ }^{(5)}$ states that a flat foot triggers knee and calcaneus valgus with consequent internal rotations of the tibia and femur, planning of the sacral spine, and increase of the lumbar, thoracic and cervical curvatures; Occurring inverse changes to the cavus foot.

The functional importance of foot landing position for biomechanics not only of the foot, but of the whole body has been demonstrated. ${ }^{\left({ }^{(6)}\right.}$ In this sense, Hunt et al. ${ }^{(7)}$ emphasize the correlation between foot landing and height of the medial longitudinal arch alteration and the index of musculoskeletal injuries, mainly determined by the location of the navicular bone. And according to Bricot ${ }^{(8)}$, any changes in the foot affects the surrounding structures through postural and mechanical reflexes.
Numerous forms of quantification and classification of the type of footprint have been described, however, a single, efficient and simple method is far from being developed. ${ }^{(9,10)}$ Plantar impressions produced by plantigraphy are among the most widespread methods, as they are easy to handle, inexpensive, have a great visual impact and can be saved for future evaluations..$^{(9)}$

In addition, several studies have carried out footprint checks through images obtained electronically by force platforms, however, some of them have demonstrated that the images obtained electronically are not representative of the plantigraphy obtained by ink. ${ }^{(9,10,11)}$

However, these methods don't do the analysis of footprint and lower limb alignment, and there is a need for a method that does so. Thus, computerized photogrammetry was developed by the application of photogrammetric principles to photographic images obtained under static conditions or during movements, being able to capture subtle bodily alterations (RICIERI, 2000). This method is used in postural evaluations due to the advantages and effectiveness of its clinical application, low cost in the image system and photointerpretation, high precision and reproducibility of the results ${ }^{(13)}$. Iunes et al. ${ }^{(14)}$ demonstrated greater reliability between the evaluations by different subjects in the postural photogrammetry in relation to the visual evaluation.

\footnotetext{
Corresponding Author: Name: Francisco Valmor Macedo Cunha. E-mail: orfeuyeuridice@yahoo.com.br

${ }^{1}$ Physiotherapist, Professor of the Physiotherapy course, Faculdade do Piaui (FAPI) and Maurício de Nassau, Teresina (PI), Brazil.

Full list of author information is available at the end of the article.
}

Financial support: The authors declare that they have no financial support.

Submission date 23 September 2016; Acceptance date 2 December 2016; Publication date 27 December 2016 
Foot changes are common and walking disorders are increasingly frequent due to sedentary habits and the use of improper shoes for long intervals of time. Thus, the importance of an accurate evaluation, as well as the determination of the foot typology, is important so that the prognosis and the best therapy can be specified. Given the cause and effect relationship between changes in the plantar arches and subsequent alterations in the structure of the lower limbs acutely, this study evaluated the relationship between foot and lower limb changes by plantigraphy and computerized photogrammetry.

\section{METHODS}

The present study consisted of a cross sectional observational study with a sample of 70 undergraduate students in Physiotherapy of education institution of a municipality in northeastern Brazil.

The sample consisted of young adults (28 males and 42 females) between 20 and 28 years of age, BMI (body mass index) between 18.5 and $25 \mathrm{~kg} / \mathrm{m}^{2}$. Sampling was non-probabilistic for convenience, in which students were included in the sample as they were located.

The study included all healthy individuals enrolled in the Physiotherapy course, with BMI classified as normal (between 18.5 and $25 \mathrm{Kg} / \mathrm{m}^{2}$ ), aged between 20 and 28 years, with no history of balance disorders or congenital malformations and diabetes.

All the ethical precepts for research with human beings were respected, following the determinations of the National Health Council (determination 196/96). The research was approved by the Research Ethics Committee of NOVAFAPI (CAAE 0239-11). Prior to the application of the questionnaire, students were informed about the purpose of the study and the procedures to which they would be submitted, and signed a Free and Informed Consent Form.

Before the evaluations, data on age and gender were recorded. Measurements of body weight (measured on the Cauduro ${ }^{\circledR}$ mechanical scale with capacity of $150 \mathrm{~kg}$ and variation of $0.1 \mathrm{~kg}$ ) And stature (determined with stadiometer coupled to the balance with variation of $0.5 \mathrm{~cm}$ ).

To perform the plantigraphy was used footprinting mat of one foot (Podaly ${ }^{\circledR}$ ), duly greased with ink and lined with A4-size white paper under the greased surface. The subject was instructed to be barefoot and, in bipodal support, place the right foot on the non-ink-stained footprinting mat and discharge the weight thereon. The process was then repeated to the left foot.

Photogrammetry of lower limbs was performed according to the methodology adopted by Trombini et $\mathrm{al}^{(4)}$. For that, the subject, dressed in bathing suits and barefoot, was positioned standing on bipodal support with an EVA (ethylene-vinyl acetate) rectangle of $7.5 \mathrm{~cm}$ between feet in $15 \mathrm{~cm}$ of a non-reflexive white background wall. The following anatomical points was demarcated by the same examiner, using small blue labels of $10 \mathrm{~mm}$ in diameter or three-dimensional markers (styrofoam balls): anterior superior iliac spine (ASIS), center of both patella, both anterior tibial tubercle, calcaneal tuberosity, lateral and medial malleolus, articular interline, first and fifth metatarsal heads, posterior superior iliac spine (PSIS).

The images were captured using a digital camera (DSC - Sony Cybershot, 12 megapixels), positioned on a tripod (Vanguard MK 4). In the frontal plane with the camera previously positioned 1 meter from the ground and 2.4 meters from the evaluated individual was evaluated the $Q$ angle and loading angle of the knee through marking the ASIS, center of both anterior patella and tibial tubercle with white markers. The lateral malleolus, the articular interline and the trochanteric tuberosity were demarcated in order to evaluate the anteroposterior alignment of the lower limbs.

In the dorsal plane, with the patient with the back on the platform, the calcaneal tuberosity and another 3 points at 4, 10 and $19 \mathrm{~cm}$ above the first were evaluated for the frontal alignment of the calcaneus were evaluated. A line coming out of the center of the first marker and passing over the center of the second was traced followed by a second straight line originating in the center of the fourth marker and passing through the third and ending in the center of the first marker three centimeters from the ground, the angle formed by the two straight lines were taken.

For frontal alignment of the forefoot, with the patient back to camera and still on the platform, the heads of the first and fifth metatarsals with three-dimensional markers were demarcated and a horizontal line was drawn on the head of the first metatarsal as a reference. The camera was positioned $90 \mathrm{~cm}$ from the student at a height of $25 \mathrm{~cm}$ from the ground.

Finally, the alignment of the da malleolar pincer was evaluated by marking the lateral and medial malleolus with three-dimensional markers; A transverse line and perpendicular to the vertical plane was drawn starting from the center of the lateral malleolus marker and another perpendicular straight line from the same point towards the center of the medial malleolus marker. Analyzes were performed in the Corel Draw ${ }^{\circledR}$ X5 2010 software.

The classification according to the footprint type was made through the Chippaux-Smirak indexes (CSI), Clarkess angle (Alfa angle), Staheli index and Cavanagh and Rodgers index. The Chippaux-Smirak index is calculated by the ratio of the width of the midfoot to the width of the forefoot. For this index, the reference values considered were: $0 \mathrm{~cm}-$ cavovarus foot; 0.01 to $0.29 \mathrm{~cm}-$ normal foot; 0.30 to $0.39 \mathrm{~cm}$ - intermediate foot; 0.40 to $0.44 \mathrm{~cm}$ - low foot and $0.45 \mathrm{~cm}$ or higher - flatfoot. ${ }^{(15)}$

The angle of the foot or Clarke's angle is characterized as the angle between the medial tangent of the foot and the most medial point of the forefoot and the apex of the arch curvature. 
The reference values are: flat (0ㅇ-29.9ㅇ), low (30ㅇ-34.9ㅇ) , intermediate (35ㅇ-41으) and normal ( $\geq 42 \circ$ ). (15) $^{(15)}$

The Staheli, Chew, and Corbett index ${ }^{(16)}$ or arch index is calculated by the ratio of backfoot to midfoot width, values being less than 1 and greater than 0.30 are considered normal, higher than 1 as flat, and lower than 0.30 as cavovarus.

The Cavanagh and Rodgers index ${ }^{(6)}$ or arch index is defined as the area of the midfoot divided by the total area of the footprint, ignoring the fingers. An arch index less than 0.21 is indicative of cavovarus foot, while a value equal to or greater than 0.26 is indicative of a flatfoot and the interval between the two values is considered normal.

Descriptive statistical analysis was performed for foot typology and general evaluation criteria. Before the performance of the hypotheses and correlation tests, normality of data distribution was evaluated by KolmogorovSmirnov test. The statistical analysis for comparing the angles between the limbs and comparisons between the gender was performed by the Student t test. To test the relationship between the biophotogrammetric categories and the footprint indexes was applied the Spearman's correlation test, and to evaluate the correlation between the categories of the same measurement was applied the Pearson's linear correlation test (footprint indexes, angles). The data are presented as mean \pm standard error of the mean and was established a value of $p<0.05$. The data were previously tabulated in the Microsoft Office Excel 2010 and the analysis performed in Prisma 5.0 software.

\section{RESULTS}

Seventy students of both genders participated in the study, and the male participants $(\mathrm{M})$ when compared to the female (F) presented significantly higher mean height $(\mathrm{M}: 1.7 \pm 0.01$; $\mathrm{F}: 1.6 \pm 0.01 ; \mathrm{p}<0.0001)$, body weight (M: $58 \pm 0.92 ; \mathrm{F}: 70 \pm 1.4 \mathrm{~kg}$; $\mathrm{p}<0.0001)$ and 42 female $\left(1.6 \pm 0.01 \mathrm{~m} ; 22 \pm 0.31 \mathrm{~kg} / \mathrm{m}^{2}\right)$ and BMI $(p<0.05)$ and 28 male $\left(23 \pm 0.42 \mathrm{~kg} / \mathrm{m}^{2}\right)$ with mean age of $21.62 \pm 2.0$ and $22.18 \pm 2.09$ years, respectively. The male participants presented statistically significant higher values

There were no statistically significant differences in footprinting mat indexes when the right and left feet were compared. The footprint indexes showed statistically significant differences regarding the Staheli $(p=0.0016)$ and the Chippaux-Smirak ( $p=0.0003$ ) indexes, adopting higher values among males (Table 1 ). In addition, another important characteristic was the disagreement in the classification of the foot typology by the different evaluation indexes used especially with regard to the Cavanagh and Rodgers index, while the other indexes maintained a margin in the normality of the footprint (Staheli - 139 normal footprint; Chippaux-Smirak - 58 normal and 55 intermediate; Cavanagh and Rodgers - 138 flat footprint; Clarke's angle - 136 normal footprint) (Table 2).

Table 3 shows a strong inverse correlation between the Staheli and Chippaux-Smirak indexes (Males - R: 0.863 and $p<0.001$; Females - R: 0.973 and $p<0.001$ ) both among male and female. In the correlation between the other indexes, significant values were not reached, showing only moderate and slight correlation.

As for the comparison of the biophotogrammetric variables presented in table 4, it was observed significantly higher values in the $Q$ angle for female $\left(22^{\circ} \pm 0.93\right.$ with $\left.p<0.0001\right)$, and knee loading angle $\left(170^{\circ} \pm 0.96\right.$ with $\left.p<0.0001\right)$ and malleolar heads angle $\left(11^{\circ} \pm 0.47\right.$ com $\left.p<0.0001\right)$ for males. It is worth noting that the values regarding the angle of alignment of the forefoot were not computed due to the significant difference between the limbs (sides) evaluated in the groups.

The evaluation of the correlation between the biophotogrammetric variables by Pearson's test revealed strong inverse correlation between $Q$ angle and the knee loading angle both male and female with correlation coefficient of -0.976 and $p<0.0001$. In others comparisons to analyze correlation there was no significant $R$ and $p$ values.

Table 5 shows the correlation between the evaluated footprint indexes and the biophotogrammetric parameters revealing significant correlation between the Cavanagh-Rodgers index and the malleolar pincer angle both male and female (Males-R: 0.386 and p 0.003; Females - R: 0.280 and p 0.010).

\section{DISCUSSION}

The analyzes of footprint indexes and photogrammetric variables were performed according to gender due to the anatomical differences presented between men and women and according to the objective of this study could result in bias. The correlation between the angles measured by biophotogrammetry and biometric data (age, weight, height and $\mathrm{BMI}$ ) are not represented because they did not

Table 1. Comparison between genders regarding the plantar arch index by Staheli, Cavanagh-Rodgers, Chippaux-Smirak and Clarke's angle methods. Teresina, 2011.

\begin{tabular}{lcc}
\hline \multicolumn{1}{c}{ Indexes } & Males $(\mathbf{n = 5 6 )}$ & Females $(\mathbf{n = 8 4})$ \\
\hline Staheli & $0.63 \pm 0.02^{*}$ & $0.55 \pm 0.02$ \\
Cavanagh-Rodgers & $0.37 \pm 0.01$ & $0.38 \pm 0.01$ \\
Chippaux-Smirak & $0.35 \pm 0.01^{*}$ & $0.30 \pm 0.01$ \\
Clarke's angle $\left(^{\circ}\right)$ & $53.00 \pm 1.0$ & $55.00 \pm 0.72$ \\
\hline
\end{tabular}

* t-Test: statistically higher value. 
Table 2. Distribution of the classification regarding the foot typology by Staheli, Chippaux-Smirak, Cavanagh-Rodgers and Clarke's angle indexes in males and females. Teresina, 2011.

\begin{tabular}{|c|c|c|c|c|c|c|}
\hline \multirow{2}{*}{ Classification by index } & \multicolumn{2}{|c|}{ Males } & \multicolumn{2}{|c|}{ Females } & \multicolumn{2}{|c|}{ Total } \\
\hline & $\mathbf{N}$ & $\%$ & $\mathbf{N}$ & $\%$ & $\mathbf{N}$ & $\%$ \\
\hline \multicolumn{7}{|l|}{ Staheli } \\
\hline Normal & 56 & 100 & 83 & 98.8 & 139 & 99.3 \\
\hline Cavovarus & - & - & 1 & 2.2 & 1 & 0.7 \\
\hline Flat & - & - & - & - & - & - \\
\hline \multicolumn{7}{|l|}{ Chippaux-Smirak } \\
\hline Normal & 12 & 21.4 & 46 & 54.8 & 58 & 41.4 \\
\hline Flat & 6 & 10.7 & 2 & 2.3 & 8 & 5.7 \\
\hline Cavovarus & - & - & - & - & - & - \\
\hline Intermediate & 30 & 53.6 & 25 & 29.8 & 55 & 39.3 \\
\hline Low & 8 & 14.3 & 11 & 13.1 & 19 & 13.6 \\
\hline \multicolumn{7}{|l|}{ Cavanagh-Rodgers } \\
\hline Normal & - & - & 2 & 2.4 & 2 & 1.4 \\
\hline Cavovarus & - & - & - & - & - & - \\
\hline Flat & 56 & 100 & 82 & 97.6 & 138 & 98.6 \\
\hline \multicolumn{7}{|l|}{ Clarke's angle } \\
\hline Normal & 55 & 98.2 & 81 & 96.4 & 136 & 97.1 \\
\hline Low & 1 & 1.8 & - & - & 1 & 0.8 \\
\hline Flat & - & - & - & - & - & - \\
\hline Intermediate & - & - & 3 & 3.6 & 3 & 2.1 \\
\hline
\end{tabular}

Table 3. Correlation between the footprint assessment methods according the gender. Teresina, 2011.

\begin{tabular}{lcccc}
\hline \multicolumn{1}{c}{ Correlation } & \multicolumn{2}{c}{ Correlation coefficient } & Females & p \\
\cline { 2 - 5 } & Males & $\mathbf{p}$ & -0.507 & $<0.001$ \\
\hline Staheli X Cavanagh-Rodgers* & -0.264 & 0.086 & 0.973 & $<0.001$ \\
Staheli X Chipaux-Smirak* & 0.863 & $<0.001$ & -0.526 & $<0.01$ \\
Cavanagh-Rodgers X Chipaux-Smirak* & -0.437 & 0.01 & 0.687 & $<0.001$ \\
Clarke's angle X Cavanagh-Rodgers" & 0.650 & $<0.001$ & -0.465 & $<0.01$ \\
Clarke's angle X Chipaux-Smirak & -0.532 & $<0.01$ & -0.432 & $<0.01$ \\
Clarke's angle X Staheli $^{*}$ & -0.451 & $<0.01$ & & \\
\hline
\end{tabular}

*Pearson's Correlation Coefficient. "Spearman's Correlation Coefficient.

Table 4. Comparison between genders for angle Q, knee loading angle, lateral alignment, malleolar angle and retrofoot alignment. Teresina, 2011.

\begin{tabular}{lccc}
\hline \multicolumn{1}{c}{ Angles } & Males $(\mathbf{n = 5 6 )}$ & Females $(\mathbf{n}=\mathbf{8 4})$ & $\mathbf{p}$ \\
\hline Q Angle & $14 \pm 0.87$ & $22 \pm 0.93^{*}$ & $<0.0001$ \\
Knee Loading Angle & $170 \pm 0.96^{*}$ & $160 \pm 0.91$ & $<0.0001$ \\
Lateral Alignment & $180 \pm 0.74$ & $180 \pm 0.47$ & $>0.05$ \\
Malleolar Angle & $11 \pm 0.47^{*}$ & $9.2 \pm 0.48$ & 0.0113 \\
Retrofoot Alignment & $4.9 \pm 0.34$ & $5.5 \pm 0.21$ & $>0.05$ \\
\hline
\end{tabular}

${ }^{*} \mathrm{t}$-Test: statistically higher value. 
Table 5. Correlation between the footprint and biophotogrammetric variables of the inferior limb alignment analyzed according to genders. Teresina, 2011.

\begin{tabular}{|c|c|c|c|c|}
\hline \multirow{2}{*}{ Correlation } & \multicolumn{4}{|c|}{ Correlation Coefficient (R) } \\
\hline & Males & p & Females & p \\
\hline Q Angle X Staheli & -0.246 & 0.068 & -0.106 & 0.339 \\
\hline Q Angle X Cavanagh-Rodgers & 0.026 & 0.848 & 0.094 & 0.395 \\
\hline Q Angle X Chipaux-Smirak & -0.158 & 0.245 & -0.127 & 0.251 \\
\hline Q Angle X Clarke's angle & 0.048 & 0.295 & -0.021 & 0.978 \\
\hline Loading Angle X Staheli & 0.300 & 0.025 & 0.110 & 0.310 \\
\hline Loading Angle X Cavanagh-Rodgers & -0.016 & 0.906 & -0.076 & 0.504 \\
\hline Loading Angle X Chipaux-Smirak & 0.233 & 0.084 & 0.142 & 0.389 \\
\hline Loading Angle X Clarke's angle & -0.059 & 0.211 & 0.034 & 0.981 \\
\hline Malleolar Angle X Staheli & -0.125 & 0.359 & -0.092 & 0.823 \\
\hline Malleolar Angle X Cavanagh-Rodgers & 0.386 & $0.003^{*}$ & 0.280 & $0.010^{*}$ \\
\hline Malleolar Angle X Chipaux-Smirak & -0.104 & 0.444 & -0.098 & 0.477 \\
\hline Malleolar Angle X Clarke's angle & 0.327 & $0.014^{*}$ & 0.120 & 0.277 \\
\hline Retrofoot Alignment X Staheli & 0.233 & 0.084 & -0.025 & 0.186 \\
\hline Retrofoot Alignment X Cavanagh-Rodgers & 0.076 & 0.578 & 0.280 & 0.495 \\
\hline Retrofoot Alignment X Chipaux-Smirak & 0.142 & 0.296 & -0.079 & 0.308 \\
\hline Retrofoot Alignment X Clarke's angle & 0.034 & 0.356 & 0.138 & 0.583 \\
\hline
\end{tabular}

*R: Spearman's Correlation Coefficient.

have significant results, probably due to the inclusion and exclusion criteria of the study, filtering individuals with BMI changes, young or old individuals, balance and other factors that influence the analyzed variables..$^{(3,17,18)}$ For the statistical analysis of correlation between the indexes of the footprint and the lower limb angles evaluated through biophotogrammetry were included only the variables whose comparison between the body dimensions were not significant $(p>0.05)$ through the paired t-test and within these circumstances, the forefoot alignment angles and lateral alignment angle were excluded from the analysis. The differences between these measures in similar members are not credited to the applied technique for data collection. According to Braz et al ${ }^{(19)}$ there are no significant differences between angular measurements performed through goniometer or photogrammetry. lunes et al ${ }^{(14)}$ evaluating the intra-examiner agreement for postural assessment through biophotogrammetry and visual evaluation observed greater agreement among the biophotogrammetry assessors. Santos et al ${ }^{(20)}$ carried out a study in order to evaluate inter and intra-examiner reliability in angular measurements by digital photogrammetry and goniometry and observed lower values of reliability through goniometry.

As for the comparison of the footprint indexes by gender, it was verified higher values in the Staheli and the Chippaux-Smirak indexes in men, Cavanagh-Rodgers and Clarke's angle indexes did not present differences when compared to men and women. Ramos, Pereira and Nucci(21) when evaluating the medial longitudinal arch in the Brazilian population in individuals aged between 10 and 59 years, observed a greater tendency of foot cavovarus in women justifying the higher values of Staheli and Chipaux-Smirak indexes in men. Complementarily, a strong correlation was observed between the Staheli and the Chippaux-Smirak indexes (Males - R: 0.863 and p <0.001; Females - R: 0.973 and $\mathrm{p}<0.001$ ) in both genders and a moderate correlation between the Cavanagh-Rodgers and the Clarke's angle indexes (Males - R: 0.650 and $p<0.001$; Females $-R: 0.687$ and $p<0.001$ ).

Another important characteristic pointed out by this study was the large amount of flat feet classified by the Cavanagh-Rodgers index (98.6\% of the evaluated footprints) in comparison with the other indexes. Hawes et al ${ }^{(22)}$ affirmed that the arc index does not reflect the actual height of the arc revealing a correlation of only 0.3 between the plantar index and height of the navicular bone measured by palpation. McCrory et al ${ }^{(23)}$ showed correlation of $50 \%$ of the evaluations through the arch index and the measurement of the height of the navicular bone through radiographic images. The flatfoot has high flexibility presenting generally pronated, since the cavovarus foot has low flexibility and inefficient impact absorption due to the total or partial non-existence of the mid-foot for the dissipation of the impact being able to generate pain in the feet and lower limbs. ${ }^{(24)}$ Azevedo and Nascimento ${ }^{(25)}$ in a study with 57 children with a mean age of 7.5 years observed a prevalence of flat footprints (59.2\%) through evaluation by the Cavanagh-Rodgers index. The authors credit the fact to the large number of obese children and to the process of physiological growth. The foot changes are risk factors to knee injuries in the compensatory 
rotating movements performed by the tibia before the foot inversion and eversion movements. ${ }^{(24)}$

In this study, only the correlation between the CavanaghRodgers and the malleolar angle index was significant $(p=0.003$ to males and 0.010 to females), but with a weak correlation level (Males - $\mathrm{R}=0.386$; Females $-\mathrm{R}=0.280$ ) according to the researched literature. Chen et $\mathrm{al}^{(26)}$ and Kanatli et al ${ }^{(27)}$ concluded by comparing radiographs and footprints that it is a simple, readily assessable, low-cost, non-invasive technique that can be used for research studies and individual clinical exams as a guide for the description of the medial arch of the foot.

In the evaluation of the correlation between the indexes was observed strong positive correlation between the ChipauxSmirak and the Staheli indexes. This fact can be explained by the fact that both indexes use as parameters the measurement of the width of the midfoot as numerators of the indexes varying only the denominator, the width of the retrofoot in the Staheli index and the forefoot in the Chippaux-Smirak index serving as constants since both undergo little changes in the medial longitudinal arch. Qamra et $\mathrm{al}^{(28)}$ demonstrated that the calcaneal and forefoot areas remain consistent even with progressive changes in the height of the medial longitudinal arch restricting footprint changes to the midfoot. In addition, moderate and positive correlation was demonstrated between Clarke's angle and the Cavanagh-Rodgers index.

The photogrammetric evaluations in this study revealed higher values in the $Q$ angle ( $22^{\circ} \pm 0.93$ with $\left.p<0.0001\right)$, loading angle $\left(170^{\circ} \pm 0.96\right.$ with $\left.\mathrm{p}<0.0001\right)$ and malleolar heads angle $\left(11^{\circ} \pm 0.47\right.$ with $\left.\mathrm{p}<0.0001\right)$ in males. Abreu, Barbosa and Coelho ${ }^{(29)}$ with the objective of evaluating the standard knee alignment in the frontal plane during the development period (12 to 17 years), found prevalence of varus knees in men and valgus in women.

The feet are the final support of the postural system and the union with the ground; Because of this, they have to adapt itself to the irregularities of the body or external environment. ${ }^{(8)}$ In this way, postural changes do not originate in and isolated way, but through the muscular chains that disrupt the body structure, triggering a chain reaction of postural adaptations that affect the most varied bodily systems. ${ }^{\left({ }^{30}\right)}$ Modifications of the muscle-ligament action can elevate or recede the foot longitudinal arches leading to biomechanical and functional alterations. $^{(31)}$ According to Bricot ${ }^{(8)}$, any deformation or asymmetry of the feet will always reflect above and will require an adaptation of the postural system. The inverse relation was demonstrated by Oliveira and Otowicz ${ }^{(32)}$ in a study performed with 41 individuals submitted to evaluation of the plantar impressions before and after osteopathic manipulation of the sacroiliac joint and observed changes in them.

All indexes are based on the premise that the footprint and, especially the midfoot, respond in a predictable way to change in the medial longitudinal arch. ${ }^{(33)}$ In this study, the correlation between the evaluation indexes of the footprint and the angles measured through biophotogrammetry did not present strong and moderate correlations, only a weak correlation between the malleolar and the Clarke's angle in men was observed $(R=0.327$ and $p=0.014)$, besides a slight correlation between the malleolar angle and Cavanagh-Rodgers index previously discussed. Contrary to the study of Trombini-Souza et al.., ${ }^{(4)}$ which assessed the correlation between lower limb alignment and Staheli index, was not found correlation with the $\mathrm{Q}$ angle.

\section{CONCLUSION}

The use of plantigraphy for evaluation and classification of the footprint is very widespread and the use of resources with greater aggregation of technology such as power platforms still seems a distant reality for most of the Brazilian centers. Studies that perform the evaluation of classification methods of the footprint and normalize these values for the Brazilian public is a strong need. The use of indexes for foot classification should be viewed with caution especially the Cavanagh-Rodgers index due to the discrepancy in the classification of flatfoot.

In this study, the correlation between the footprints indexes and the changes of the lower limb alignment was not significant. However, new studies are needed using special populations (obese, diabetic, pregnant) and individuals with known footprints changes so that the existing correlations can be established. In this research, the low correlation can be credited to the use of narrow and normal exclusion criteria such as BMI and absence of other alterations already specified.

\section{AUTHOR'S CONTRIBUTION}

Francisco Valmor Macedo Cunha - data collection, photos analysis and statistical analysis. Tárik Augusto Amorim Rodrigues- Data collection and analysis of plantigraphy. Jonas de Almeida Alves - Data collection and article review. Jean Douglas Moura dos Santos - Data collection (biophotogrammetry) and article review. Maria do Carmo de Carvalho e Martins - Article review and statistical analysis.

\section{CONFLICTS OF INTEREST}

The authors declare that they have no conflicts of interest.

\section{AUTHOR DETAILS}

${ }^{2}$ Physiotherapist, Specialist Intensive Physiotherapy. ${ }^{3}$ Physiotherapist, Master in Genetics and Toxicology (ULBRA). Professor of the Physiotherapy course, Faculdade do Piauí (FAPI), Teresina (PI), Brazil. ${ }^{4}$ Physiotherapist, Specialist Musculoskeletal Physiotherapy. Master in Biomedical Engineering (UNIVAP), São José dos Campos (SP), Brazil. Professor of the Physiotherapy course, Centro Universitário Uninovafapi (UNINOVAFAPI), Teresina (PI), Brazil. ${ }^{5}$ Nutritionist, PhD in Physiology (UFPE). Professor of the Federal University of Piaui (UFPI), Picos (PI), Brazil and Centro Universitário Uninovafapi (UNINOVAFAPI), Teresina (PI), Brazil.

\section{REFERENCES}

1 Hernandez AJ, Kimura LK, Laraya MHF, Fávaro E. Cálculo do índice do arco plantar de Staheli e a prevalência de pés planos: estudo em 100 crianças entre 5 e 9 anos de idade. Acta ortopédica brasileira. 2007;15(2):68-71.

2 Pezzan PAO, Sacco ICN, Silvia MAJ. Postura do pé e classificação do arco plantar de adolescentes usuárias e não usuárias de calçados de salto alto. Revista brasileira de fisioterapia. 2009;1(5):398-404. 
3 Krishan K. Establishing correlation of footprints with body weightForensic aspects, Forens Scien Internat. 2008;179:63-69.

4 Trombini-Souza F, Ribeiro AP, Iunes DH, Monte-Raso VV. Correlações entre as estruturas dos membros inferiores. Fisioter Pesq. 2009;16(3):205-210.

5 Carvalho JA. Órteses: um recurso terapêutico complementar. Barueri - SP: Manole, 2006.

6 Mccrory JL, Young MJ, Boulton AJM, Cavanagh PR. Arch index as a predictor of arch height. Foot. 1997;7:79-81.

7 Hunt AE, Fahey AJ, Smith RM. Static measures of calcaneal deviation and arch angle as predictors of rearfoot motion during walking. Aust J Physiother. 2000;46:9-16.

8 Bricot B. Posturologia. 2 ed. São Paulo: Icone, 2001.

9 Urry SR, Wearing SC. The Accuracy of footprint contact area measurements: relevance to the design and performance of pressure platforms. The Foot. 2001;11:151-157.

10 Urry SR, Wearing SC. Arch indexes from ink footprints and pressure platforms are different. Foot. 2005;15:68-73.

11 Cantalino JLR, Mattos HM. Análise das impressões plantares emitidas por dois equipamentos distintos. ConScientiae Saúde. 2008;7(3):367-372.

12 Ricieri DV. Validação de um protocolo de fotogrametria computadorizada e quantificação angular do movimento tóracoabdominal durante a ventilação tranqüila. Dissertação (Mestrado) - UNITRI, Uberlândia: Centro Universitário do Triângulo, 2000.

13 Ribeiro AP, Trombini-Souza F, lunes DH, Monte-raso VV. Confiabilidade inter e intra-examinador da fotopodometria e intra-examinador da fotopodoscopia. Revista Brasileira de Fisioterapia. 2006;10(4):435-439.

14 Iunes DH, Bevilaqua-grossi D, Oliveira AS. Análise comparativa entre avaliação postural visual e por fotogrametria computadorizada. Revista Brasileira de Fisioterapia. 2009;13(4):308-315.

15 Nikolaidou ME, Boudolos KD. A footprint-based approach for the rational classification of foot types in young schoolchildren. The Foot. 2006; 16: 82-9.

16 Staheli LT, Chew DE, Corbett M. The longitudinal arch. A survey of eight hundred and eighty-two feet in normal children and adults. The Journal of Bone and Joint Surgery. 1987;69:426-428.

17 Gaymer C, Whalley H, Achten J, Vatish M. Midfoot plantar pressure significantly increases during late gestation. The Foot 2009;19:114-116.

18 Rodriguez N, Volpe RG. Clinical diagnosis and assessment of the pediatric pes planovalgus deformity. Clin Podiatr Med Surg 2010;27:43-58.
19 Braz RG, Goes FPDC, Carvalho GA. Confiabilidade e validade de medidas angulares por meio do software para avaliação postural. Fisioterapia Mov. 2008;21(3):117-126

20 Santos JDM, Oliveira MA, Silveira NJF, Carvalho SS, Oliveira AG. Confiabilidade inter e intraexaminadores nas mensurações angulares por fotogrametria digital e goniometria. Fisioter Mov. 2011;24(3):389-400

21 Ramos GM, Pereira SRF, Nucci A. Avaliação computacional da impressão plantar valores de referência do índice do arco em amostra da população brasileira. Acta fisiatr.2007;14(1):7-10.

22 Hawes MR et al. Footprint parameters as a measure of arch height. Foot Ankle internat. 1992;13(1);22-26.

23 Mccrory JL, Young MJ, Boulton AJM, Cavanagh PR. Arch index as a predictor of arch height. Foot. 1997;7:79-81.

24 Guimarães GV, Freitas HFG, Silva PRS, Teixeira LR. Pés: devemos avaliálos ao praticar atividade físico-esportiva? Rev Bras Med Esporte. 2000;6(2):57-59.

25 Azevedo LAP, Nascimento LFC. A distribuição da força plantar está associada aos diferentes tipos de pés? Rev Paul Pediatr. 2009;27(3):30914.

26 Chen $\mathrm{CH}$, Huang $\mathrm{MH}$, Chen TW, Weng MC, Lee CL, Wang GJ. The correlation between selected measurements from footprint and radiograph of flatfoot. Arch. Phys. Med. Rehabil. 2006;87:235-240.

27 Kanatli $\mathrm{U}$, Yetkin $\mathrm{H}$, Cila E. Footprint and radiographic analysis of the feet. J. Pediatr. Orthop. 2001;21(2):225-228.

28 Qamra SR, Deodhar SD, Jit I. Podographical and metrical study for pes planus in a Northwestern Indian population. Human Biology. 1980;52:435-445.

29 Abreu AV, Barbosa JRP, Coelho JFP. Alinhamento dos joelhos no plano frontal dos 12 aos 17 anos. Rev Bras Ortop. 1996;31(1):83-88.

30 Castro PCG, Lopes JAF. Avaliação computadorizada por fotografia digital, como recurso de avaliação da reeducação postural global. Acta Fisiatr. 2003;10(2):83-88.

31 Tanaka C, Farah E. Anatomia funcional das cadeias musculares. São Paulo: Ícone, 1997.

32 Oliveira AP, Otowicz I. Análise do apoio dos pés no chão e a sua correlação com as disfunções biomecânicas da articulação ílio-sacra. Terapia Manual. 2004;2(3):122-127

33 Mathieson I, Upton D, Birchenough A. Comparison of footprint parameters calculated from static and dynamics footprints. The Foot. 1999;9(1):145149. 